\title{
A FENOMENÓLOGA DE GÖTTINGEN: BREVE RELATO DE TRAJETÓRIA DA FENOMENOLOGIA NA VIDA DE EDITH STEIN
}

\author{
The phenomenology of Göttingen: a brief review of phenomenology \\ trajectory in the life of Edith Stein
}

\author{
Elisangela Pereira Machado*
}

\begin{abstract}
Resumo: Na efervescência, como também, no silêncio de debates acerca do feminino e do papel da mulher na sociedade contemporânea, mais especificamente, no universo acadêmico, o presente artigo tem por intuito apresentar a relevante participação de uma mulher multifacetada. Mulher que, durante o período da I Guerra Mundial, rompe com o beco de uma filosofia androcêntrica, torna-se membro do Círculo de Göttingen organiza as investigações fenomenológicas do fundador deste estilo de pesquisa, um dos maiores filósofos do início do século XX: Edmundo Husserl. A partir dessas concebe - uma fenomenologia original, em diálogo com o pensamento tomista. Edith Stein, judia, ateia, filósofa, educadora, teóloga e mártir dilata o campo de pesquisa fenomenológica que se restringia à ciência e à psicologia e contribui no avanço das reflexões referentes à educação e à teologia. Suas investigações rompem a barreira do tempo de sua época e chegam até nossos dias, instigando o pensamento atual no que diz respeito ao ser humano e do seu lugar no mundo.
\end{abstract}

Palavras-chave: Mulher, Fenomenologia, Interdisciplinaridade, Contemporaneidade.

\begin{abstract}
In the effervescence, as well as in the silence of debates about the feminine and the role of women in contemporary society, more specifically in the academic universe, this article intends to present the relevant participation of a multifaceted woman. A woman who, during the period of the I World War, breaks with the alley of an androcentric philosophy, becomes a member of the Göttingen Circle, organizes the phenomenological investigations of Edmund Husserl, founder of this style of research, one of the greatest philosophers of the early twentieth century. She conceives, from these - an original phenomenology in dialogue with Thomist thought. Edith Stein, Jewish, atheist, philosopher, educator, theologian and martyr - expands the field of phenomenological research that was restricted to science and psychology and contributes to the advancement of reflections on education and theology. Her investigations break the barrier of the time of her time and come to this day, instigating current thinking regarding the human being and his place in the world.
\end{abstract}

Keywords: Woman, Phenomenology, Interdisciplinarity, Humanism, Contemporaneity.

\footnotetext{
* Mestra em Filosofia/UNISINOS. Doutoranda em Teologia sistemática pela Pontifícia Universidade Católica do Rio Grande do Sul - PUCRS. Bolsista CNPq. E-mail: elispmachado@gmail.com
}

\begin{tabular}{|c|c|l|l|c|c|}
\hline intuitio & $\begin{array}{c}\text { ISSN } \\
1983-4012\end{array}$ & Porto Alegre & Vol.10- $\mathrm{N}^{\circ} .2$ & $\begin{array}{c}\text { Dezembro } \\
2017\end{array}$ & p. 96-107 \\
\hline
\end{tabular}




\section{Introdução}

Transitar por entre as ciências é se deparar com o exercício da curiosidade humana e com o fluir alternado do espanto e do silêncio, diante de perguntas e respostas que nos atingem na jornada de nossa caminhada existencial. Nossa curiosidade é surpreendentemente diversa, e, desde Aristóteles, com as suas quatro aitia - termo grego que denomina as quatro causas ${ }^{1}$ que o filósofo classificou em suas investigações, queremos respostas que sanem ou amenizem as problematizações que elencamos na vida, sejam elas simplórias inquietações do cotidiano ou elaboradas indagações filosóficas.

Em uma busca surpreendente da verdade, Edith Theresa Hedwing Stein foi uma figura marcante de um espírito fortemente especulativo que transitou pelos corredores de algumas das principais ciências preponderantes do século XIX, a saber, história, psicologia, filosofia, teologia. Ela certamente, escutou de seus colegas professores, de seus estudantes e, especialmente, do interior de si mesma a inquietante questão 'diga-me por quê??'. E, por não aceitar reducionismos, bem como relatam suas obras e a sua biografia, ela sempre se dedicou com afinco à busca pela essência última de suas inquietudes. Uma vida marcada pela vivacidade de espírito e curiosidade, empática frente as questões do humano e da sua inserção na sociedade. Stein nasceu na cidade de Breslau (antiga Alemanha, atualmente Polônia) aos 12 de outubro de 1891 numa família de origem judaica. Quando atinge a idade crítica da adolescência, começam a aflorar uma infinidade de questionamentos em relação à religião, à maneira de ver o mundo e às respostas que lhes eram dadas.

Entre as idas e vindas da escola, devido ao seu descontentamento com os esclarecimentos que ofereciam, Stein, finalmente, encontra a sua alma mater na Universidade, espaço onde realizará projetos e alimentará o desejo de esclarecer o máximo possível, mediante suas investigações, o enigma do ser humano. Filósofa desde a medula, como a caracterizam alguns de seus biógrafos, ela irá vislumbrar em sua trajetória de vida um cenário que contribuiria em suas inquietações viscerais filosóficas e no desdobramento de seu pensamento, escolhas e produção intelectual. O centro de atenção era o problema da existência da humanidade e o sentido da vida do homem².

Isso se dá devido ao fato de que a sociedade em que viveu Stein, passava por tremendas mudanças econômicas, socioculturais que influenciaram todo o pensamento ocidental. O século XIX é marcado pelo entrelaçamento de teorias científicas e ideias filosóficas. Ela estava presente e, celebrou, com certeza, quando as mulheres começavam a participar mais efetivamente das decisões políticas, uma vitória para as

${ }^{1} \mathrm{O}$ quê, onde, quando, por quê e como? As quatro causas da tradição grega especuladas pela observação de Aristóteles: de que matéria alguma coisa é feita, ou a sua causa material? Que forma essa matéria assume? O início? Como foi sua causa eficiente? Qual seu propósito, meta ou fim? Cf. DENNETT, 1998, p. 23.

${ }^{2}$ STEIN, Edith. Obras Completas: Escritos autobiográficos e cartas. Vol. I. Madrid/Burgos: Vitoria Ediciones El Carmen/ Editorial de Espiritualidad e Editorial Monte Carmelo, 2002a, p. 47.

\begin{tabular}{|c|c|c|c|c|c|}
\hline intuitio & $\begin{array}{c}\text { ISSN } \\
1983-4012\end{array}$ & Porto Alegre & Vol.10- No.2 & $\begin{array}{c}\text { Dezembro } \\
2017\end{array}$ & p. 96-107 \\
\hline
\end{tabular}


feministas existentes em toda Europa pós-guerra. Entretanto, passando por períodos de destruição e reconstrução a Alemanha marchava para um quadro crítico em 1933 quando Hitler assumiu o governo.

Ao final do século XIX a ciência que se destacava era a psicologia que desenvolvia investigações mediante problemáticas junto das áreas da teoria do conhecimento e da lógica. Nesse período, teve destaque um grande filósofo reconhecido como o responsável pela inauguração do movimento filosófico da fenomenologia, a saber, Edmund Husserl (1859-1938). Considerados herdeiros da modernidade, temos como partícipes da escola fenomenológica, Alfred Schutz (1899- 1959), Max Scheler (1874-1928), Martin Heidegger (1889-1976), Karl Jaspers (1883-1969) e, enquanto figura feminina de destaque - a própria: Edith Stein (1891-1942).

Stein toma conhecimento da fenomenologia quando o professor neo-kantiano Höniswald, em um seminário em que ela participava, lê artigos sobre a novidade que vinha se destacando em Munique e, que em um anúncio de periódico, dizia ter espaço para a mulher no movimento da nova corrente de pensamento denominada: fenomenologia. O grupo em questão era liderado pelos professores Adolf Reinach (1883-1917) e Edmund Husserl (1859-1938), desse modo, o anúncio da proposta levou Stein, movida impulsivamente pelos seus anseios de verdade, a devorar textos de Husserl e se inscrever para um semestre na Universidade de Göttingen - berço do novo movimento citado e porta de entrada para a nova vida que ela iria experienciar até as últimas consequências ${ }^{3}$.

Para Stein, a entrada no mundo da fenomenologia se dá de um modo extraordinário e repleto de circunstâncias que a surpreenderam, bem como, as pessoas próximas que a cercavam. O professor Reinach que havia compreendido e assimilado profundamente o método fenomenológico, liderava o movimento de estudantes de Göttingen e, foi o primeiro a acolher a jovem Stein e celebrar com ela o seu ingresso após uma entrevista com o próprio Husserl.

Depois dos avisos gerais chamou os novatos, um por um. Quando lhe disse meu nome, ele acrescentou: "Dr. Reinach tem me falado sobre você. Você tem lido algo meu"? "As investigações lógicas. Todas as investigações lógicas, inclusive o segundo tomo completo". Inclusive o segundo tomo? Então você é uma heroína. Disse Husserl sorrindo. Assim fui admitida ${ }^{4}$.

Começa uma intensa vida acadêmica que irá não apenas redirecionar toda a vida de Edith Stein, mas também, de toda filosofia restrita no universo das correntes tidas como racionalismo, empirismo e transcendentalismo, uma nova possibilidade de posicionar-se diante do mundo e de falar sobre ele, o mundo da vida - sem proselitismos, um revolucionário percurso de investigação. Um estilo de linha de pesquisa em que o ser humano mediante consciência, tem por tarefa buscar a essência, o sentido último

\footnotetext{
${ }^{3}$ STEIN, Edith. Obras Completas: Escritos autobiográficos e cartas. Vol. I. Madrid/Burgos: Vitoria Ediciones El Carmen/ Editorial de Espiritualidad e Editorial Monte Carmelo, 2002a, p. 48.

${ }^{4}$ Ibid., p. 354
}

\begin{tabular}{|c|c|c|c|c|c|}
\hline intuitio & $\begin{array}{c}\text { ISSN } \\
1983-4012\end{array}$ & Porto Alegre & Vol.10-N N .2 & $\begin{array}{c}\text { Dezembro } \\
2017\end{array}$ & p. 96-107 \\
\hline
\end{tabular}


dos fenômenos ${ }^{5}$. O método fenomenológico no exercício de escavação rumo ao essencial, deixa de lado o que é acessório e acidental para alcançar a verdade vivida que brota da análise e de reflexões rigorosas. O sentido das coisas é descrito mediante a capacidade humana de refletir diante do que lhe é mostrado, como as coisas físicas e, ou abstratas. É esse método, ou melhor, esse estilo de linha de pesquisa que irá acompanhar Edith Stein em todo desenvolvimento de sua produção intelectual, obras e conferências. Isso porque, para nossa filósofa, fazer fenomenologia é aprender a descrever as coisas, é chegar ao coração da essência da coisa, apreender a essência mesma e, daí poder então mencionar que se sabe algo sobre o que enunciamos e cremos compreender.

Portanto, nosso caminho será o sistemático, teremos de fixar nossa atenção nas coisas mesmas e ir construindo sobre esta base na medida que pudermos. Para isso, naturalmente, temos de proceder de acordo com um método determinado (...) O método com o qual tratarei de solucionar os problemas é o fenomenológico. Quer dizer, o método que Edmundo Husserl elaborou e empregou pela primeira vez no tomo II de suas investigações lógicas, por que estou convencida, e já havia sido empregado por grandes filósofos de todas as épocas, se bem que não de modo exclusivo e com uma clara reflexão sobre o modo de proceder (...) O princípio elementar deste método é fixar a atenção nas coisas mesmas, não interrogar a teoria sobre as coisas, deixar fora o quanto possível tudo que seja ouvido ou lido (...) mas, beber da intuição imediata ${ }^{6}$.

Com efeito, se constata que toda a investigação steiniana está sob a égide da fenomenologia. Um estilo de pesquisa rigoroso presente na vida pessoal e intelectual de Edith Stein, uma mulher singular, que soube avançar corajosamente em um período conflitivo, encontrou seu espaço e, escavou fundo, mediante o método investigativo que tratamos, sobre o sentido da vida, Husserl não investia em temas que a filósofa tinha como relevantes. Stein fez do método um caminho para chegar ao mais fundo possível do mundo do homem, de sua essência e de seu possível devir. E em tudo, seu mestre, o filósofo matemático Husserl a acompanha, influenciando suas investigações e escolhas, mesmo quando Stein rompe com este e apresenta, de modo originário, um novo rumo para a fenomenologia, não fica mais possível mencionar Edith Stein sem Husserl e, sequer mencionar Husserl sem agradecer a Edith Stein.

\section{A fusão da razão indagadora - do moderno ao medievo}

No universo de pesquisa acadêmica brasileira, Edith Stein ainda é pouco conhecida. Quando mencionada, ela sempre é citada como assistente de Edmund Husserl no auge do período da formação do círculo dos estudantes de fenomenologia de Göttingen. Entretanto, Stein foi bem mais do que isso. O

\footnotetext{
${ }^{5}$ A noção de fenômeno tem origem no termo latim - Phaenomenon que, por sua vez, deriva de um conceito grego

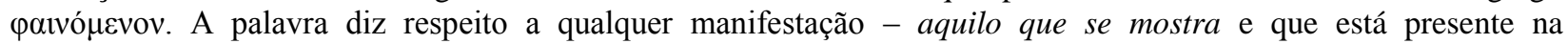
consciência de um sujeito que é objeto da sua percepção.

${ }^{6}$ STEIN, Edith. Obras Completas: Escritos antropológicos e pedagógicos. Vol. IV Madrid/Burgos: Vitoria Ediciones El Carmen/ Editorial de Espiritualidad e Editorial Monte Carmelo, 2003, p. 590.
}

\begin{tabular}{|c|c|l|l|c|c|}
\hline intuitio & $\begin{array}{c}\text { ISSN } \\
1983-4012\end{array}$ & Porto Alegre & Vol.10- No.2 & $\begin{array}{c}\text { Dezembro } \\
2017\end{array}$ & p. $96-107$ \\
\hline
\end{tabular}


A Fenomenóloga de Göttingen: Breve Relato de Trajetória da Fenomenologia na vida de Edith Stein

caminho até o gênio alemão Husserl não foi de um fácil percurso. Entre os trabalhos acadêmicos que deveriam ser entregues das disciplinas que cursava anteriormente, Stein dedicava-se, seriamente, a leitura da obra fundante da fenomenologia, as Investigações Lógicas (Logische Untersuchungen - 1900/01) daquele que viria a tornar-se o seu doctor father, a saber, o pai doutoral da tese de doutorado intitulada Sobre o problema da empatia ${ }^{7}$ (Zum Problem der Einfühlung, 1917).

Afinal, a fenomenologia tornou-se a teoria mais debatida e difundida na década de $1920 \mathrm{em}$ toda a Europa e, surgia como uma nova técnica de abordar toda gnosiologia e liberar o terreno da atitude de pesquisa predominante da época muito presente na Alemanha, a saber, o positivismo, que reivindicava o primado do que é concreto em nome da pesquisa científica de tipo experiencial e constatável ${ }^{85}$. Admitida no círculo de Göttingen, que consistia em um grupo de jovens estudiosos interessados em aprofundar e desenvolver o método fenomenológico, Stein tomou conhecimento da crise das ciências da época, das questões em relação ao idealismo e realismo, dos critérios do positivismo e das medidas do cientificismo. Impressionada com a obra de Husserl, fez dele seu primeiro mestre e da fenomenologia seu suporte investigativo.

Quando as investigações lógicas de Husserl apareceram pela primeira vez se teve a impressão de que com elas se dava as costas a forma de pensar criticista da filosofia moderna e se regressaria as grandes tradições da philosophia perennis. Estava resolvido o problema com o ceticismo nas diferentes formas que se manifestava (psicologismo, historicismo) e se esboçou a ideia de uma ontologia formal (...) E a escola de Göttingen de Husserl que aderiu a esse standard work viu nas investigações ontológicas sua tarefa própria ${ }^{9}$.

Para os fenomenólogos, a realidade cotidiana não era confiável, mas, não se podia refutá-la no imediatismo da compreensão humana, por isso, o método enquanto caminho de refutações e esclarecimentos, contribuiria no desvelar dos verdadeiros fundamentos de toda ou qualquer visão de mundo. Não há mais separação entre o mundo e a consciência do mundo, a razão pode agora falar sobre o mundo com mais solidez. O desejo pela verdade tornou-se uma novidade com sentido. Vale destacar o fato de que - Stein não assimilou passivamente as ideias husserlianas, inúmeras vezes, em sua obra e biografia. Ela expõe suas discordâncias em debates com o próprio Husserl, isso porque, jamais se permitiu ficar restrita às noções do mestre e, prosseguindo sempre, delineava sua própria acepção do estilo de linha de pesquisa fenomenológica.

Há um período estanque na vida acadêmica de Stein que não será aqui abordado na riqueza de seus detalhes. Este ocorre quando ela assume um voluntariado como enfermeira na Cruz Vermelha no

\footnotetext{
${ }^{7}$ A filósofa trata do problema da condição epistemológica onde se estabelece o mínimo de comunicação afetiva, a inclinação ao outro que supera o solipsismo, constatado mediante análise de atos de vivência - experiências universais. Para tanto, Cf. STEIN, 2002b, p. 82.

${ }^{8}$ Cf. BELLO, Angela Ales. Edmund Husserl: pensar Deus, crer em Deus. São Paulo: Paulus, 2016, p.18.

${ }^{9}$ STEIN, Edith. Obras Completas: Escritos antropológicos e pedagógicos. Vol. IV Madrid/Burgos: Vitoria Ediciones El Carmen/ Editorial de Espiritualidad e Editorial Monte Carmelo, 2003, p. 995.
}

\begin{tabular}{|c|c|c|c|c|c|}
\hline intuitio & $\begin{array}{c}\text { ISSN } \\
1983-4012\end{array}$ & Porto Alegre & Vol.10- $\mathrm{N}^{\circ} .2$ & $\begin{array}{c}\text { Dezembro } \\
2017\end{array}$ & p. 96-107 \\
\hline
\end{tabular}


A Fenomenóloga de Göttingen: Breve Relato de Trajetória da Fenomenologia na vida de Edith Stein

período do início da Primeira Guerra Mundial, adiando assim o seu doutoramento que somente será concluído em Friburgo aos 3 de agosto de 1916, quando ela retorna para os estudos com Husserl e que a instiga a realizar o Rigorosum, a saber, um minucioso e difícil exame para obtenção do doutorado. Ela o faz e adquire o título de Doutora com summa cum laude. Depois disso, Stein emprega seu tempo integral para a filosofia, introduzindo jovens estudantes no método fenomenológico e organizando os escritos e anotações do pensamento de Husserl, no intento de serem publicados e ela, enfim, ser reconhecida nesta parceria $^{10}$.

Todavia, ainda que a fenomenologia husserliana a tivesse tirado do campo do descontentamento intelectual, da insatisfação interior em relação às ciências, chegou um tempo em que Edith não conseguiu mais prosseguir apenas como auxiliar do filósofo. Ela almejava mais. Desejava uma produção em reciprocidade, educar, mas, devido ao fato de ser mulher, isso não acontecia. Mesmo que acolhida e respeitada por Husserl, este, vivia cada vez mais imerso em suas reflexões, distante e, não muito aberto a diálogos. A filósofa mesma partilha em uma de suas correspondências:

(...). Em relação ao mestre, querido senhor Kauffmann, há ocasiões em que não é fácil manter o equilíbrio adequado, algo que tenho experimentado a fundo durante os dois anos de relação de proximidade pessoal. Tenho de reconhecer, sem dúvida, de que é ele quem mais tem sofrido das consequências do fato de entregar a sua vida inteira à ciência. Isto é algo tão assombroso e o que se tem de agradecer tão inestimável que não é possível surgir nenhum sentimento de ofensa pessoal. Para mim, pessoalmente, ele segue sendo o mestre, cuja imagem nenhuma fraqueza humana pode manchar $(\ldots)^{11}$.

Stein decidiu deixar o cargo de assistente, decisão que ela também relata em suas cartas e que o mestre viu com bons olhos a sua retirada, e lhe escreveu, muito amavelmente, mesmo que com um certo ar de reprovação, em seu desabafo na carta ela termina escrevendo - 'agora estou livre e penso que isso é bom, mesmo que não me sinta no momento muito feliz ${ }^{12}$. A partir do evento da retirada de Stein do cargo de auxiliar de Husserl, inicia a via de elaboração e desenvolvimento de uma concepção autônoma e original de fenomenologia steiniana que amplia e dilata a importância da fenomenologia, não somente na época da filósofa em questão, mas, no limiar dos desafios de nossa contemporaneidade.

Se Husserl foi para Edith Stein o primeiro mestre a aprimorar a sua busca da verdade, Tomás de Aquino (1225-1274) tornou-se o segundo e um dos principais responsáveis pela virada existencial da filósofa. A fenomenologia em Stein era um caminho para, primeiramente, compreender o sentido da própria fenomenologia, depois, com o estilo husserliano, Stein avança e encontra na patrística e escolástica razões para melhor desenvolver o mesmo. Sem dúvida alguma, para ela, Husserl e Aquino tornaram-se cânones da filosofia perene, da autêntica força motriz filosofal, eles são duas clareiras de

${ }^{10}$ STEIN, Edith. Obras Completas: Escritos autobiográficos e cartas. Vol. I. Madrid/Burgos: Vitoria Ediciones El Carmen/ Editorial de Espiritualidad e Editorial Monte Carmelo, 2002a, p. 489.

${ }^{11}$ Ibid., p. 689.

${ }^{12}$ Op. cit., p. 606.

\begin{tabular}{|c|c|c|c|c|c|}
\hline intuitio & $\begin{array}{c}\text { ISSN } \\
1983-4012\end{array}$ & Porto Alegre & Vol.10-N N.2 & $\begin{array}{c}\text { Dezembro } \\
2017\end{array}$ & p. 96-107 \\
\hline
\end{tabular}


saberes de suas respectivas épocas. As investigações destes dois homens, de períodos que se diferem completamente, são impulsionadas pela mesma busca da verdade, busca aprofundada no movimento de uma ciência rigorosa que não é produto da sensibilidade, fantasia, especulação ou mera opinião, mas, tarefa visceral de uma razão indagadora.

O contato com Tomás de Aquino, o pensador medieval, um dos pais de toda uma escola da tradição religiosa, a saber, a escolástica do Cristianismo, ocorre em circunstâncias da vida pessoal de Edith Stein em que ela muda radicalmente seu modo de viver e pensar. O interesse pela tradição escolástica e a patrística é despertado intensamente depois de uma experiência em que a filósofa vive na casa de amigos - quando numa noite de insônia, desce a biblioteca da casa em que pernoitava e, aleatoriamente, pega um livro para distrair-se. Stein atravessa a noite lendo uma obra sobre a vida da carmelita Santa Teresa d'Ávila, considerada doutora da Igreja e mística ${ }^{13}$. De ascendência judaica e até então ateia, ao amanhecer, após a leitura do livro, Edith exclama para seus amigos: - encontrei a verdade! Após o evento citado, em pouco tempo, ela se converte ao catolicismo e se dedica com afinco aos estudos da escolástica, especialmente, em Tomás de Aquino no qual ela irá realizar um diálogo com o pensamento de Husserl. A orientação básica da fenomenologia de ir às coisas mesmas (Zur Sachen selbst), de buscar os fundamentos primeiros do conhecimento, desarmando-se de conhecimentos anteriores, abriu caminho para Stein reencontrar-se com a religião. De ascendência judaica e até então ateia, Stein retoma uma dimensão de seu ser, até então esquecida, abandonada pela mesma, a dimensão espiritual.

O seu processo de abandono do judaísmo e reencontro com a religião cristã, bem como o seu itinerário dentro da vida monástica carmelita, é um processo que exige tempo, leitura, aprofundamento e respeitosa reflexão. O presente artigo não irá se deter nessa nova fase steiniana, mesmo sendo merecedora de nossa curiosidade e atenção. O que se almeja salientar é da intensa busca pela verdade que moveu Stein e que a conduziu à fenomenologia enquanto possibilidade abrangente e rigorosa de investigação dos fenômenos que a auxiliaram nesta mesma busca e, em um encontro com um destino admirável resultante da escolha radical pelo ser humano e dos dilemas da contingência de seus dias.

A incansável busca da verdade que sempre impulsionou Edith Stein é uma busca em aberto, tanto em Husserl como em Tomás de Aquino, a fenomenóloga em sua originalidade vai se dedicar em suas investigações a unir este anseio e possibilidades, pois, a ratio husserliana não elimina a ratio do Aquinate $^{14}$. A fé abre a razão a verdades que são inacessíveis pela razão, a filosofia, ao aderir à fé, não se

\footnotetext{
${ }^{13} \mathrm{O}$ ano era 1921, Edith estava na casa do amigo protestante Von Martin de férias na Baviera. Ela então lê a autobiografia de Santa Teresa d'Ávila nesta noite de insônia, segundo Sciadini 'um livro errado, numa casa errada e numa biblioteca errada'. Cf. SCIADINI, Patricio. O heroísmo de Edith Stein. In: Cidade Nova, dezembro de 1998, p.17.

${ }^{14} 7$ Aquinate denomina o conjunto da obra de Tomás Aquino - coisas do Aquino - sua obra e os estudos filosóficos teologais. Para Aquino há uma distinção entre razão natural e razão sobrenatural enquanto em Husserl faz uso de argumentos da razão natural no combate ao ceticismo de seu tempo.
}

\begin{tabular}{|c|c|c|c|c|c|}
\hline intuitio & $\begin{array}{c}\text { ISSN } \\
1983-4012\end{array}$ & Porto Alegre & Vol.10 - No.2 & $\begin{array}{c}\text { Dezembro } \\
2017\end{array}$ & p. 96-107 \\
\hline
\end{tabular}


contradiz, pois ela não só clama pela verdade, mas pelo conjunto todo da verdade; em outras palavras, ela clama pela maior certeza que o espírito humano pode expressar em nível de manifestação. Stein promove um encontro entre o medieval e o moderno desenvolvendo uma concepção autônoma de fenomenologia. Para ela, os dois autores se complementam no debruçar de suas investigações a fim de descobrir algo do Logos, do poder da ratio.

Ela o faz porque a fenomenologia não é uma ciência dedutiva, não parte de um núcleo de princípios indemonstráveis, tampouco é indutiva, pois não busca verdades universais por meio da generalização de um conjunto de proposições particulares. A fenomenologia funda-se a partir do método intuitivo, mediante este é possível captar as verdades da fé que são infinitas, imutáveis e evidentes. É o resgate da noção de verdade absoluta e da objetividade da consciência, a retomada de que a verdade é imutável e de que o espírito deve encontrá-la ao invés de produzi-la. Ela escreve ainda,

O objetivo da fenomenologia é a clarificação e com ela a fundamentação última de todo conhecimento. Para se chegar a este objetivo é preciso que seja excluído de toda consideração todo o duvidoso. Não faz uso dos resultados de ciência alguma, isto faz parte de sua compreensão porque uma ciência que almeja ser clarificação última de todo conhecimento científico, não pode apoiar-se por sua vez sobre uma ciência já fundamentada, mas que se deve fundar em si mesma ${ }^{15}$.

Desse modo, a fenomenologia está em oposição à busca por uma verdade mutável, que se modifica com o tempo e de acordo com determinadas condições, isso faz com que a investigação filosófica perca seu rigor investigativo, a verdade é una com suas nuances e possibilidades de esclarecimento e a tarefa da fenomenologia é a de fundamentar o conhecimento em bases seguras mediante os dados que nos são oferecidos à consciência no percurso da contingência humana real. No intuito de resgatar o verdadeiro sentido da investigação filosófica e recuperar a fé na razão, Stein aborda textos que fazem uma relação conciliatória da fenomenologia com a tradição escolástica. Ela procura diminuir o abismo entre os filósofos católicos e os modernos, pois para a filósofa, a falta de intercâmbio entre estes grupos sempre foi nociva para a filosofia.

No tocante à sua adesão ao pensamento do Aquinate, Stein traça um paralelo entre este e Husserl acerca da investigação sobre a substância/essência nas obras dos dois filósofos. Mais ainda, numa fase madura de seu pensamento, ela também irá aprofundar o conceito de pessoa para desenvolver uma fenomenologia de cunho antropológico teológico na associação dos conceitos - essência e pessoa ${ }^{16}$.

${ }^{15}$ STEIN, Edith. Obras Completas: Escritos Filosóficos. Vol.II. Madrid/Burgos: Vitoria Ediciones El Carmen/ Editorial de Espiritualidad e Editorial Monte Carmelo, 2002b, p. 79.

${ }^{16}$ Diluídas em seus escritos de filosofia e antropologia, Edith Stein seguirá toda uma linhagem conceitual oriunda de Boécio, Ricardo de São Vítor e Tomas de Aquino para extrair um conceito de pessoa - Racionalidade e espiritualidade unidos ao conceito de pessoa enquanto individualidade e reciprocidade, uma espiritualidade somada a apercepção de valores e ao potencial para alcançar a plenitude do desenvolvimento do ser anímico caminhante, o tema da pessoa na reflexão steiniana não será aqui desenvolvido.

\begin{tabular}{|c|c|c|c|c|c|}
\hline intuitio & $\begin{array}{c}\text { ISSN } \\
1983-4012\end{array}$ & Porto Alegre & Vol.10- N.2 & $\begin{array}{c}\text { Dezembro } \\
2017\end{array}$ & p. 96-107 \\
\hline
\end{tabular}


Sempre carregando em si admiração e gratidão a Husserl, Edith Stein buscou no método uma oportunidade de realizar uma investigação mais precisa acerca do ser humano em sua complexidade - uma antropologia que respondesse mais claramente sobre o fenômeno humano em diálogo com as demais ciências como chaves interpretativas no percurso de sua pesquisa rigorosa. Um caminho diferenciado, mas em unidade com tudo o que busca definir, da melhor forma possível, o ser humano e sua relação com o mundo. Isto porque, para Stein, não havia dúvidas de que o objetivo primordial da fenomenologia é o da clarificação, um esclarecimento mais definido da essência das coisas e abertura desafiante à possibilidade de, na complexidade dos temas que suscitam a inquietude humana, a interdisciplinaridade poderá vir a sanar a fragmentação dos saberes.

\section{Um filtro para a superficialidade rasa do hoje}

Não é difícil a constatação de que não há água rasa no mar steiniano. Toda a obra de Edith Stein são relatos de quem escreve sob um impulso interior irresistível resultado de uma vida de autêntica busca pela verdade. Desde o início de sua jornada intelectual, Stein estava segura de que era necessário encontrar um método que edificasse a filosofia, para que esta merecesse, verdadeiramente o nome de ciência. Esse objetivo resultou na ambição fenomenológica o ir à essência última das coisas para uma melhor compreensão dos desdobramentos sucessivos do pensamento. Portanto, a fenomenologia steiniana sempre se propôs a desenvolver o romper, ou melhor, o libertar-se das filosofias relativistas vigentes de seu tempo, apreender o fenômeno em sua essência pura, desligado de todas as contingências do aparecer.

A possibilidade de um filtro rigoroso para especulações e falsas certezas, abertura de caminho para o diálogo das verdades desveladas. O caminho da fenomenóloga de Göttingen não foi um breve passeio pelo universo das ciências e de suas indagações. Stein esteve lá, numa trajetória pessoal única, que revela a sua notável apreensão da fenomenologia. Ela nos provoca, em sua posição independente, de mulher intelectual, mesmo quando imersa em um movimento específico, não romper com o mesmo, mas, avançar e promover um diálogo ousado e maduro com o outro - uma soma de saberes e concepções que ampliam a compreensão do humano - do lugar e do sentido do homem no mundo. Emerge uma nova visão de mundo que procura, insaciavelmente, os fundamentos de toda e qualquer outra visão minimalista da realidade, estilo investigativo que analisa os pressupostos de que se utilizam as diversas áreas em suas tentativas de explicar o mundo e, faz entender, esclarecer aquilo que é.

A novidade é a redescoberta constante e o avançar da fidelidade em relação ao espírito da pesquisa filosófica que procura o sentido dos fatos, indo além de todas as formações culturais, mas, que estancam na superfície da realidade. Neste ponto, Stein nos admoesta para o verdadeiro sentido da importância da fenomenologia no mundo das ciências, uma fenomenologia que desafie o reducionismo e a

\begin{tabular}{|c|c|c|c|c|c|}
\hline intuitio & $\begin{array}{c}\text { ISSN } \\
1983-4012\end{array}$ & Porto Alegre & Vol.10- $\mathrm{N}^{\circ} .2$ & $\begin{array}{c}\text { Dezembro } \\
2017\end{array}$ & p. 96-107 \\
\hline
\end{tabular}


superficialidade das opiniões ingênuas já formadas acerca de tudo. Nela é possível vislumbrar o impacto da fenomenologia no pensamento filosófico de uma época, uma visão do mundo que é global e que desafia a uma análise séria do modo de contemplar e falar sobre este mundo. Uma escavação emergente do sentido último das coisas em um tempo em que nada mais é aprofundado. A trajetória de Stein pela psicologia, história, filosofia, antropologia e teologia fez dela alguém com knowground para contribuir na investigação acerca da pessoa humana e das questões referentes ao sentido do ser - do $e u$ em relação ao mundo. Nossa filósofa se utiliza do estilo fenomenológico e desenvolve uma antropologia que se dilata para além do cogito, que se dá conta de que na esfera das vivências há de se considerar toda uma relação entre as dimensões da imanência e da transcendência para um ser integral pleno.

Stein busca sanar as visões errôneas acerca do método fenomenológico que o reduziram e confundiram como sendo uma retomada dos grandes sistemas filosóficos antigos, a saber, o platonismo, o aristotelismo e a escolástica. A fenomenologia para a filósofa de Göttingen se caracteriza pelo resgate da ideia de verdade absoluta e objetividade da consciência, verdade imutável que o espírito deve encontrar e não produzir. Para isso, a fenomenologia steiniana elabora e aprofunda três importantes pontos, a objetividade da consciência, a intuição enquanto método e a questão do idealismo em que Stein realiza toda uma discussão com o chamado giro idealista ${ }^{17}$ de Husserl. Recorrendo a análises da fenomenologia realista desenvolvidas por sua amiga Hedwig Conrad Martius (1888-1966), Stein busca sanar as divisões mediante argumento de que a fenomenologia não implica um idealismo, pois o idealismo é resultado de uma metafísica pessoal de Husserl e não produto de uma investigação fenomenológica, ou seja, uma decisão a respeito do ser e sua relação com a consciência que deve ser rigorosa em relação ao que nos é dado em forma de evidências.

O intento da filósofa, bem como de Husserl, é de, a um só tempo, ser realista e idealista, valorizando o debate de ambas as correntes e fornecendo uma prova da independência ôntica do ser no mundo num compromisso realista em relação à experiência da intersubjetividade. Stein dá continuidade à fenomenologia husserliana, mas, amplia a sua abertura à investigação metafísica, considerando o subjetivismo do idealismo transcendental uma consequência natural de todo trabalho fenomenológico. A discussão entre o idealismo e o realismo do círculo de Göttingen não será aprofundando no presente texto; o intento é de traçar o percurso existencial de Edith Stein enquanto mulher fenomenóloga e dos dilemas que a mesma enfrentou e buscou esclarecer com sua bagagem acadêmica e existencial. É um convite para um contato mais preciso com as suas obras, para melhor compreender o modo como fazia uso do estilo

17 A questão polêmica do embate entre idealismo e realismo na fenomenologia dividiu o movimento dos fenomenólogos, os estudantes do círculo de Göttingen, não concordavam com a visão não compatível de cunho realista presente no Tomo I das Ideias com a ideia de verdade absoluta das investigações lógicas de Husserl. Edith Stein irá buscar conciliar alguns pontos entre as duas, mostrando não haver uma ruptura absoluta entre as duas obras, pois, nas Investigações já estavam presentes questões que conduziram a fenomenologia à questão transcendental.

\begin{tabular}{|c|c|l|l|c|c|}
\hline intuitio & $\begin{array}{c}\text { ISSN } \\
1983-4012\end{array}$ & Porto Alegre & Vol.10- $\mathrm{N}^{\circ} .2$ & $\begin{array}{c}\text { Dezembro } \\
2017\end{array}$ & p. 96-107 \\
\hline
\end{tabular}


fenomenológico, para desenvolver toda uma argumentação a respeito das investigações e debates que lhes eram solicitados.

Stein em suas obras e conferências buscou, exaustivamente, fazer justiça ao fenômeno diminuindo abismos entre os fenômenos e as coisas em si, no retorno à crença natural na existência no mundo. Há nela, não uma contradição, mas, complementariedade. Para tal intento, promove aproximações de Husserl e Scheler, Husserl e Heidegger, Husserl e Kant, destacando os principais contrastes e pontos de apoio em sua trajetória reflexiva. A fenomenologia steiniana é uma fenomenologia husserliana, contudo, vasta e, em um diálogo de profundidade com outras ciências e concepções filosóficas. Há em Stein uma originalidade e autonomia resultantes de todo um processo investigativo, esforço da mesma em encontrar a verdade última das coisas, das quais, ela mesma em sua jornada pessoal, afirma e dá testemunho de ter encontrado. Um desejo de objetivação, de filtrar e analisar do melhor modo possível tudo o que é dado à consciência sanando a superficialidade de nossas falsas certezas.

Em um tempo em que tudo parece incerto e o pensamento desliza insensível no instante de falsas certezas, a fenomenologia steiniana corrobora como uma proposta de filtro da consciência ingênua. Um estilo investigativo adequado na busca por precisão, no processo que envolve todo humano, na apreensão do objeto-matéria e do verdadeiro significado do que se vê com o que, verdadeiramente, é de fato. É um conhecimento que se dá, parcialmente e, no processo progressivo e vivencial. Assim sendo, a verdade para Edith Stein é compreendida não mais como mera opinião, mas como um saber, um saber que descansa no ser verdadeiro, fundado em si mesmo. Se a tarefa da filosofia é o esclarecimento, porque se recusa e não se contenta com resultados provisórios, a fenomenologia é instrumento primordial do qual Stein soube muito bem fazer uso.

\section{Conclusão}

Não há como negar, neste ponto, que a fenomenologia foi um método constante na vida de Edith Stein, ela foi uma representante importante dentro da escola fenomenológica e sua jornada tem início em Göttingen quando foi membro do círculo de estudantes fenomenólogos e auxiliar de Edmund Husserl. As ideias expressas acima são apenas uma gota no vasto oceano da fenomenologia steiniana. Para realizar um estudo completo de suas obras, teríamos de dar conta de todos os seus escritos onde ela dialoga com a filosofia cristã e com os místicos. Consideremos um convite introdutório para conhecermos melhor esta mulher singular, até então, pouco conhecida no campo da filosofia, mas, que muito pode contribuir no campo filosófico, pedagógico e teológico de nossos dias.

A filosofia é uma ciência rigorosa, não uma questão de sentimentos, imaginação, entusiasmos, opiniões ou gostos pessoais. A reflexão filosófica tem condições de satisfazer aos mais altos quesitos

\begin{tabular}{|c|c|c|c|c|c|}
\hline intuitio & $\begin{array}{c}\text { ISSN } \\
1983-4012\end{array}$ & Porto Alegre & Vol.10 $-\mathrm{N}^{\circ} .2$ & $\begin{array}{c}\text { Dezembro } \\
2017\end{array}$ & p. 96-107 \\
\hline
\end{tabular}


científicos e superar a tagarelice elegante que a acompanha ao longo dos anos e, das tradições que em nossos dias, parecem cada vez mais distantes de uma honestidade intelectual amadurecida. A presença de Edith, tanto na filosofia quanto na teologia contemporânea, ainda é uma presença silenciosa e tímida. Mas, ela está emergindo aos poucos, e, com suma importância, mediante a solidez, no alicerce da sua proposta e argumentação ela nos aponta possibilidades de rompermos com atitudes meramente especulativas da existência. É preciso ir além da reflexão do mundo, porque nele estamos e nele somos. Em um tempo liquefeito, em que quase todos anunciam a morte, o desmoronamento de tudo - inclusive, da razão, Edith Stein propõe um sério e profundo reposicionamento diante de si e do mundo, este viveiro de incertezas que aprisiona a capacidade humana de ir além, sem perder a si mesma.

\section{Referências}

BELLO. A. A. Edmund Husserl. Pensar Deus, crer em Deus. São Paulo: Ed. Paulus, 2016.

RUS. Éric. A visão educativa de Edith Stein. Aproximação a um gesto antropológico integral. Belo Horizonte/MG: Ed. Artesã, 2015.

SANTANA, L. Edith Stein, a construção do ser pessoa humana. São Paulo: Ed. Ideias\&Letras, 2016.

SBERNA, A. A. A formação da Pessoa em Edith Stein. Um percurso de conhecimento do núcleo interior. São Paulo: Ed. Paulus, 2015.

SCIADINI, P. O heroísmo de Edith Stein. In: Cidade Nova, 1998.

STEIN, E. Obras Completas: Escritos autobiográficos e cartas. Vol. I. Madrid/Burgos: Vitoria Ediciones El Carmen/ Editorial de Espiritualidad e Editorial Monte Carmelo, 2002a.

Obras Completas: Escritos Filosóficos. Vol.II. Madrid/Burgos: Vitoria Ediciones El Carmen/ Editorial de Espiritualidad e Editorial Monte Carmelo, 2002b.

Obras Completas: Escritos antropológicos e pedagógicos. Vol. IV Madrid/Burgos: Vitoria Ediciones El Carmen/ Editorial de Espiritualidad e Editorial Monte Carmelo, 2003.

JUSTO, H. Edith Stein. Itinerário fascinante de uma judia católica, filósofa, vítima do nazismo. Canoas: UNILASALLE, 2006.

Recebido em: 25/10/2017

Aprovado para a publicação em: 20/11/2017

\begin{tabular}{|c|c|l|l|c|c|}
\hline intuitio & $\begin{array}{c}\text { ISSN } \\
1983-4012\end{array}$ & Porto Alegre & Vol.10- No.2 & $\begin{array}{c}\text { Dezembro } \\
2017\end{array}$ & p. 96-107 \\
\hline
\end{tabular}

